\title{
Effects of two physical therapy interventions in patients with chronic non-specific low back pain: feasibility of a randomized controlled trial
}

\author{
Efeitos de duas intervenções fisioterapêuticas em pacientes com dor lombar \\ crônica não-específica: viabilidade de um estudo controlado aleatorizado
}

Alessandra N. Garcia', Francine L. B. Gondo², Renata A. Costa², Fábio N. Cyrillo², Leonardo O. P. Costa',3

\begin{abstract}
Background: Chronic non-specific low back pain is both a health and a socio-economic problem which is associated with disability as well as with emotional distress. The McKenzie and Back School's techniques have been shown to be effective in the treatment of this condition. Objectives: To perform a preliminary analysis of the effects of these treatments in patients with chronic non specific low back pain for the following outcomes: pain, disability and trunk flexion range of motion and to test the feasibility of randomized controlled trial testing these interventions on this population. Methods: The participants were assessed by a blinded assessor and randomly assigned into one of the treatment groups. The data analysis was performed in only 18 patients and the study is still ongoing, so the results are restricted to these patients, as a single group. Results: The patients improved for the outcomes pain intensity (mean difference of 2.4 points and $95 \% \mathrm{Cl} 0.84$ to 3.93 ) and disability (5.2 points and $95 \% \mathrm{Cl} 2.55$ to 7.78 ), but no improvement in range of motion in flexion was observed (7.2 degrees $95 \% \mathrm{Cl}-1.82$ to 16.29). Conclusion: The McKenzie and Back School's approaches may be beneficial for the treatment of patients with chronic non specific low back pain for the outcomes pain intensity and disability. We also concluded that the study is feasible and we will continue performing the current study without any adjustments of the original research protocol. This study was prospectively registered in the Australian New Zealand Clinical Trials Registry (ANZCTR) number ACTRN12610000435088.
\end{abstract}

Keywords: low back pain; Back School; McKenzie; physical therapy; rehabilitation.

\section{Resumo}

Contextualização: A dor lombar crônica não-específica é um problema de saúde associado à redução do desempenho funcional e a alterações emocionais. Os métodos Back School e McKenzie têm se mostrado eficazes no tratamento desse sintoma. Objetivos: Realizar uma análise preliminar da eficácia dessas técnicas em pacientes com dor lombar crônica não-específica para os desfechos intensidade da dor, desempenho funcional e amplitude de movimento (ADM) de flexão de coluna e testar a viabilidade da condução de um estudo controlado aleatorizado utilizando essas intervenções nessa população. Métodos: Os indivíduos foram avaliados por um examinador cego e distribuídos aleatoriamente para os grupos de tratamento. A análise dos dados foi realizada em 18 pacientes, e o estudo continua em andamento, portanto os resultados apresentados se referem a esses pacientes como sendo de um só grupo. Resultados: Os pacientes obtiveram melhora nos desfechos intensidade da dor (média das diferenças de 2,4 pontos e IC a 95\% - 0,84 a 3,93) e desempenho funcional (5,2 pontos e IC 95\% - 2,55 a 7,78), mas não para a ADM de flexão de coluna (7,2 graus e IC 95\% - 1,82 a 16,29). Conclusão: Os métodos Back School e McKenzie podem ser benéficos no tratamento de indivíduos com dor lombar crônica não-específica. Além disso, concluiu-se que o estudo é viável e continua sem alterações no projeto inicial. Estudo previamente registrado no Australian New Zealand Clinical Trials Registry (ANZCTR) sob o número ACTRN12610000435088.

Palavras-chave: dor lombar; Back School; McKenzie; fisioterapia; reabilitação.

Received: 05/27/2011 - Revised: 06/10/2011 - Accepted: 06/16/2011 


\section{Introduction $: \because:$}

Chronic non-specific low back pain (low back pain lasting for at least 12 weeks) ${ }^{1}$ is a major health and socioeconomic problem that is responsible for work absenteeism, reduced functional performance ${ }^{2}$, emotional distress ${ }^{3}$ and high economic costs for its treatment ${ }^{2}$. The point prevalence of low back pain ranges from 12 to $33 \%^{4}$, the prevalence of low back pain over the last 12 months ranges from 22 to $65 \%$ and the lifetime prevalence ranges from 11 and $84 \%^{4}$. A cohort study involving 406 patients with chronic low back pain observed that $43 \%$ of patients with acute low back pain developed chronic low back pain, and only a third of these patients recovered within a year ${ }^{5}$.

In most clinical practice guidelines, supervised exercise therapy has proven to be effective in reducing pain and improving functional performance in the treatment of patients with chronic non-specific low back pain ${ }^{1,6,7}$. The Back School and McKenzie's methods are good options of active therapy, which use specific exercises for the treatment of low back pain, as well as theoretical information aimed at educating the patients, so that they will be able to better understand their conditions and to learn how to modify their behavior with regards to low back pain ${ }^{8-10}$.

At present, we are conducting a randomized controlled trial, comparing the effect of these two techniques in 148 patients with chronic low back pain. The present article shows the results of the first phase, which is a feasibility study with 18 participants so that it will be possible to analyze its progress. The objective of the randomized controlled trial is to compare the effects of the Back School and McKenzie's techniques in patients with chronic non-specific low back pain for the following outcomes: pain intensity, disability and trunk flexion range of motion (ROM). As this study has not yet been completed, the specific aim of this study was to assess its feasibility, showing its progress and, additionally, to identify whether there is a improvement in these patients with chronic non-specific low back pain, regardless the intervention allocated.

\section{Methods $: \because$.}

\section{Ethics approval and trial registration}

This feasibility study was conducted between July and September 2010 in the Physical Therapy Clinic of the Universidade Cidade de São Paulo (UNICID), São Paulo, SP, Brazil, approved by the Committee of Ethics in Research of the UNICID (Resolution 196/96 of the National Health Council - research protocol No. 13469394), registered prospectively at the Australian and New Zealand Clinical Trials Registry (ACTRN12610000435088) and the research protocol published ${ }^{11}$. This manuscript presents a feasibility study of this randomized controlled trial that is currently in progress.

\section{Sample size calculation}

The sample size calculation for the main study was calculated to detect a difference of 1 point for the pain intensity outcome, measured by the Numerical Rating Scale (NRS) ${ }^{12}$ (with an estimated standard deviation of 1.84 points) and 4 points for the disability outcome, measured by the Roland Morris Disability Questionnaire ${ }^{13,14}$ (estimated standard deviation of 4.9 points). A statistical power of $80 \%$, alpha of $5 \%$ and a possible sample loss of up to $15 \%$ were considered for the sample size calculation of both outcomes. Therefore, 74 patients per group (total of 148 patients) will be recruited. The present study shows the results of the first 18 patients that were recruited.

\section{Eligibility criteria}

Eighteen participants were recruited either through community advertisements as well as by referrals from orthopedic surgeons. Patients with non-specific low back pain, with at least three months of duration and aged between 18 and 80 years were included. Participants who had any contraindications to physical exercise, according to the guidelines of the American College of Sports Medicine ${ }^{15}$; with serious spinal pathologies (fractures, tumors and inflammatory diseases, such as ankylosing spondylitis); nerve root compromise (e.g. cauda equina syndrome); severe cardiopulmonary diseases or pregnancy ${ }^{3}$ were excluded.

\section{Assessment procedures}

Patients were welcomed by the therapist responsible for the assessment and eligibility of participants. Patients were informed about the study objectives and eligibility criteria and then they signed the consent form. Four assessment instruments were used: 1) a personal characteristics questionnaire in which was recorded the initial date of treatment, personal data of the patients, clinical characteristics and results of the assessment of the McKenzie's method ${ }^{16}$; 2) the Pain Numerical Rating Scale (NRS ${ }^{12}$, in order to measure pain intensity); 3) Roland Morris Disability Questionnaire ${ }^{14}$ for the assessment of disability associated with low back pain, and 4) fleximeter ${ }^{17}$ to assess the trunk flexion range of motion (ROM). Pain intensity and disability were considered as primary outcomes and the trunk flexion ROM was considered as a secondary outcome. 
The assessor of the study was unaware of the treatment that patients received. Obviously, patients and the therapists were not blinded to the treatment allocation.

\section{Instruments}

\section{Pain Numerical Rating Scale (NRS)}

The Pain NRS is an instrument translated and adapted into Brazilian Portuguese ${ }^{12}$, which assesses the levels of pain intensity perceived by the patient through an 11-point scale (ranging from 0 to 10), being 0 classified as "no pain" and 10 as "the worst pain possible"12. The participants were asked to report their levels of pain intensity based upon the last seven days.

\section{Roland Morris Disability Questionnaire}

The Roland Morris Disability Questionnaire is an instrument translated and cross-culturally adapted into Brazilian Portuguese $\mathrm{P}^{13,14}$. It is widely used in research and clinical practice to assess disability associated with low back pain. It comprises of 24 items that describe everyday situations which patients have difficulty to perform due to low back pain. The greater the number of questions satisfied, the greater the disability. Subjects were instructed to complete the items that describe them over the last 24 hours ${ }^{14}$.

\section{Fleximeter}

The fleximeter (Fleximeter ${ }^{\circledR}$ ) is a device based on a mechanism of gravity action, used to measure flexibility and joint ROM through an angular scale ${ }^{17}$. Because it is an instrument that does not contain joint vertices, but a Velcro which is secured in the joint, it allows to isolate a variety of joint movements, ensuring greater accuracy for the measures ${ }^{17}$. The trunk flexion ROM was measured with the patient standing, knees extended and arms crossed over the chest ${ }^{17}$. The fleximeter was positioned laterally in the thoracic region at the chest height, with the display facing the assessor ${ }^{17}$. The patients were instructed to bend the trunk forward until the maximum range of motion ${ }^{17}$

\section{Randomization}

Immediately after the assessment, the patients were referred to the therapist responsible for the treatment, which was informed about the direction of preference for the the McKenzie's method. If the patient was allocated to the Back School group, this information would only be recorded on his/her assessment form, but unused. Before starting the treatment, patients were randomly allocated into their treatment groups (Back School or McKenzie) according to a randomization schedule generated by computer and carried out by a researcher who was not involved with the recruitment and treatment of participants. The allocation of subjects was concealed through a random numerical sequence concealed in numbered, sealed and opaque envelopes. The therapist responsible for the treatment, before starting the interventions, opened the envelope in front of the patient and informed him/her about the technique corresponding to the number on the envelope. The sealed envelopes waiting for new patients were kept in a safe place, to which only the researcher responsible for randomization had access.

\section{Interventions}

Considering that the Back School method recommends four sessions of treatment, the same number of sessions was used for the McKenzie's method group, in order to standardize the total time of treatment for both groups, since there is no consensus in the literature about optimal number of sessions. In total, this first part of the study consisted of three steps, considering the baseline assessment, four days of treatment (once a week) and the four weeks follow-up.

\section{Back school group}

The participants allocated to the Back School group received four treatment sessions, once a week, lasting on average 45 minutes to an hour ${ }^{10,18}$. On the first day of treatment the sessions were held individually to respect the randomization process performed immediately after the initial assessment. The remaining sessions were conducted in groups. The program was provided based on theoretical and practical information ${ }^{10,18}$ (Appendices 1 and 2).

\section{McKenzie group}

The participants allocated to the McKenzie group received four individual sessions of treatment, once a week, lasting on average 45 minutes to an hour. The exercises were defined from the result of the assessment performed prior to the randomization step and guided according to the preferred direction of movement, i.e., flexion, extension or lateral displacement of the spine ${ }^{16}$. The program was provided based on theoretical and practical information ${ }^{16,19}$ (Appendices 1 and 2).

\section{Preliminary analysis}

Since this feasibility study consists of a preliminary analysis of the randomized controlled trial, we chose to not corrupt the 
randomization at this early stage of the study, in order to avoid possible changes in the behavior of the therapist responsible for providing the interventions, which might affect the trustworthiness of the final results. Therefore, the results of intervention of each technique were presented as a single group. At the end of the study, the randomization codes will be opened to show the results of the between-group differences. Therefore the interpretation of the results from this manuscript should be understood as an analysis of the effectiveness of exercises recommended by the McKenzie and Back School methods and, therefore, should be interpreted with caution until final results of the study are published.

\section{Statistical analysis}

The analysis of preliminary results was performed using paired samples Student's t test. The data for all outcomes were normally distributed. The level of significance set for this study was 0.05 (5\%). The remaining analyses presented in this study are descriptive. For the statistical analysis, the softwares SPSS V18, SigmaPlot V10 and MS Office Excel 2007 were used.

\section{Results $: \therefore$.}

The study included 18 patients with chronic non-specific low back pain, being 14 women and four men, with a mean age of 49 years. Most of the sample consisted of married, nonsmoking, sedentary, with high school education people. These participants had previous episodes of low back pain and were taking medication to control their symptoms. To date, from a total of 72 sessions of treatment were performed (i.e. four sessions per patient) only four sessions were missed (mean of sessions performed $=3.78, \mathrm{SD}=0.55$ ). In addition, so far, there was no loss of follow-up.

Data collection of the baseline assessment lasted approximately one hour. A longer data collection duration for the patients allocated to the McKenzie's method was observed. In the reassessment, conducted after the fourth treatment session, the duration of the follow-up was on average 20 minutes. There was no loss of follow-ups for the pain intensity and disability outcomes. It was not possible to collect information with regards to the trunk flexion ROM outcome for one patient. Therefore, it can be implied that the interventions have been well received by patients, who were engaged with the interventions. The characteristics of the participants and the beseline and post-treatment estimates are shown in Tables 1 and 2, respectively.

At the beginning of the study, pain intensity was 6.4 points decreasing at the end of treatment to 4 points (Table 2 and
Figure 1), with a difference of 2.4 points (95\% confidence interval $=0.84$ to $3.93 ; p=0.005$ ). Likewise, there was an improvement in disability (Table 2 and Figure 1). With regards to the trunk flexion ROM, no improvement was observed $(\mathrm{p}=0.11$ ) (Table 2 and Figure 1).

\section{Discussion $\because:$.}

This feasibility study aimed to show the progress of a randomized controlled trial from mapping patients' adherence to the treatments and procedures regarding data collection. Similarly, we sought to identify whether there is an improvement in these patients with chronic non-specific low back pain for the outcomes pain intensity, disability and trunk flexion ROM, regardless of the intervention allocated. Thus, the results were presented as a single group. Of the 18 first patients included in the study, two did not undergo to one of the treatment sessions and one did not present for two treatment sessions. All participants who missed these treatment sessions justified their absences due to personal reasons. Despite not having received all treatments, all patients were followed up properly over the phone.

It was observed a shorter duration of data collection for the follow up assessment of four weeks than the baseline assessment, probably because, there was no need for a reassessment with the McKenzie's method, which required longer time during the initial assessment. There was no loss of follow-up for the pain intensity and disability outcomes; however, there was a loss of follow up for the trunk flexion ROM outcome.

After four treatment sessions, patients improved in terms of pain intensity (mean difference between baseline and after treatment of 2.4 points (on a scale of 11 points) and 95\% Confidence interval $=0.84$ to $3.93 ; \mathrm{p}=0.005$ ) and disability (mean difference between baseline and after treatment of 5.2 points (on 0-24 point scale) and 95\% Confidence interval $=2.55$ to $7.78, \mathrm{p}=0.001$ ), but not for the outcome of trunk flexion ROM $(p=0.11)$. The interpretation from this study is that, on average, the Back School and McKenzie's methods can be understood to be strategies that can beneficial for patients with chronic non-specific low back pain at short-term follow up, which is consistent with previous studies, which demonstrates the benefits of the techniques in reducing pain and improving disability in the short and medium-term follow ups ${ }^{10,20}$.

In a systematic review ${ }^{21}$ which investigated the effectiveness of the McKenzie's method in the treatment of chronic low back pain compared with other interventions found results in favor of the McKenzie's method for the pain intensity and disability outcomes in the short-term. When the McKenzie's method was compared to passive therapies, stabilization exercises 
and strengthening exercises, results were found in its favor in reducing pain and improving disability in the short-term ${ }^{21}$. Heymans et al. ${ }^{10}$ systematically reviewed the effectiveness of the Back School method in the treatment of patients with chronic non-specific back pain. Most studies showed positive results in the short and medium-term for the Back School method in reducing pain and improving disability, when compared with other exercise approaches, manipulation, myofascial therapy and placebo ${ }^{10}$.

The Back School and McKenzie's methods include not only exercise as a form of intervention, but they also include a theoretical component ${ }^{10,20}$. The literature shows that education enable patients to have access to knowledge of health behavior that influence learning and how to deal with the adverse health conditions, such as low back pain, and how to cope with its symptoms?.

With regards to trunk flexion ROM, another outcome investigated in this study, no statistically significant difference was observed. In the McKenzie's method, when assessing the patient's response to any technique, not only the symptomatic presentation, but also the mechanical presentation (such as trunk ROM) should be considered. Skikic and $\mathrm{Suad}^{22}$, studying the effects of the McKenzie's method in low back pain, observed statistically significant differences in the improvement of trunk mobility. Similarly, Andrade, Araújo and Vilar ${ }^{23}$ observed improvements in trunk flexion ROM in the short-term, using the Back School method as an intervention. Toscano and Egypto ${ }^{24}$ found that sedentary people
Table 1. Characteristics of the sample.

\begin{tabular}{|c|c|}
\hline Variables & \\
\hline Gender & \\
\hline Female & $14(77.8)$ \\
\hline Male & $4(22.2)$ \\
\hline Age (years) & $49.1(13.78)$ \\
\hline Low back pain duration (months) & $91.5(122.21)$ \\
\hline Weight (kilos) & $78.4(14.01)$ \\
\hline Height (meters) & $1.65(0.07)$ \\
\hline Marital Status & \\
\hline Single & $6(33.3)$ \\
\hline Married & $11(61.1)$ \\
\hline Widow & $1(5.6)$ \\
\hline Education & \\
\hline Completed primary school & $6(33.3)$ \\
\hline Completed high school & $10(55.6)$ \\
\hline Completed university degree & $2(11.1)$ \\
\hline Use of medication & \\
\hline Yes & $11(61.1)$ \\
\hline No & $7(38.9)$ \\
\hline Currently doing exercise & \\
\hline Yes & $5(28)$ \\
\hline No & $13(72)$ \\
\hline Smoking status & \\
\hline Yes & $3(16.7)$ \\
\hline No & $15(83.3)$ \\
\hline Recent episode of low back pain & \\
\hline Yes & $12(66.7)$ \\
\hline No & $6(33.3)$ \\
\hline Pain intensity $(0-10)$ & $6.4(2.81)$ \\
\hline Disability (0-24) & $13(5.30)$ \\
\hline Trunk range of motion in flexion (degrees) & $84(20.39)$ \\
\hline
\end{tabular}

Categorical variables are expressed as numbers and percentages. Continuous variables are expressed as means and standard deviations.

Table 2. Values obtained at baseline and after treatment, between-group differences and their respective $95 \%$ confidence intervals for the outcomes pain intensity, disability and range of motion.

\begin{tabular}{lcccc}
\hline Outcomes & $\begin{array}{c}\text { Baseline } \\
\text { mean }(\mathrm{SD}) \mathrm{n}=18\end{array}$ & $\begin{array}{c}\text { Post-treatment } \\
\text { mean }(\mathrm{SD}) \mathrm{n}=18\end{array}$ & $\begin{array}{c}\text { Difference } \\
95 \% \mathrm{Cl}\end{array}$ & $\mathrm{p}$ \\
\hline Pain intensity $(0-10) \mathrm{n}=18$ & $6.4(2.81)$ & $4.0(2.95)$ & $2.4(0.84$ to 3.93$)$ & 0.005 \\
\hline Disability (0-24) $\mathrm{n}=18$ & $13.0(5.30)$ & $7.8(5.96)$ & $5.2(2.55$ to 7.78$)$ & 0.001 \\
\hline Trunk flexion ROM (degrees) $\mathrm{n}=17$ & $82.9(20.44)$ & $90.1(10.79)$ & $7.2(-1.82$ to 16.29$)$ & 0.110 \\
\hline
\end{tabular}
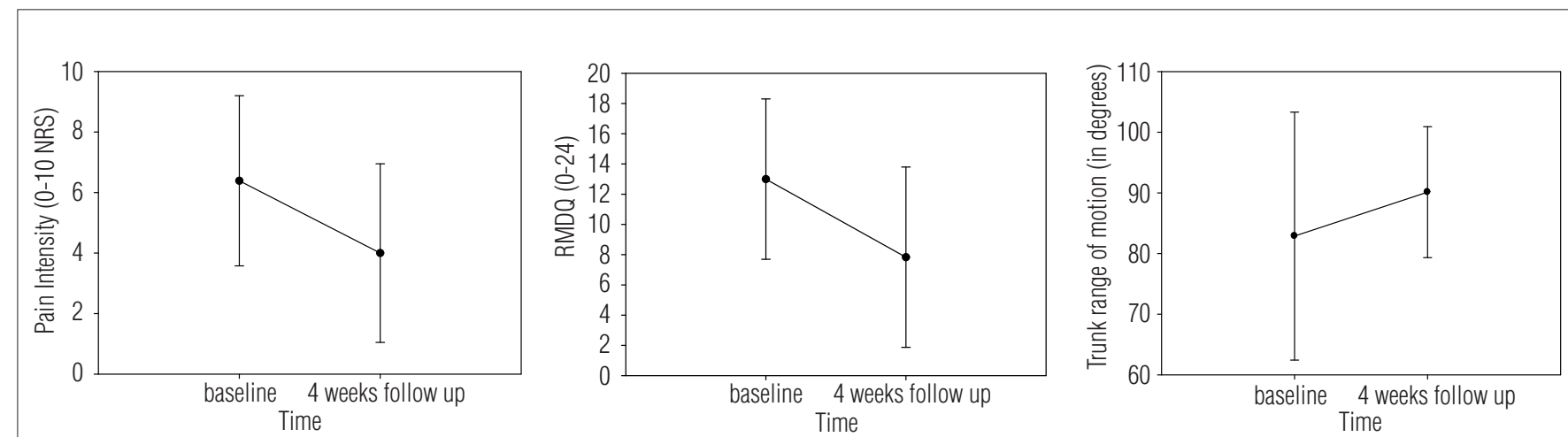

High scores represent greater pain intensity, greater disability and greater range of motion. NRS: Numerical Rating Scale. RMDQ: Roland Morris Disability Questionnaire. Data expressed as means and standard deviations.

Figure 1. Results of pain intensity. disability and range of motion (mean and SD). The measures were obtained at baseline and after 4 sessions of treatment. 
(one of the characteristics of the participants who comprised the sample of the present study) have reduced trunk range of motion. They concluded that the improvement of ROM has been associated to the relief of symptoms. So, it is expected, in this study that, associated with a reduction in pain intensity, it would be identified at the end of four weeks an improvement in ROM, but at this stage this change was not observed.

\section{Conclusion $: \because$.}

With this feasibility study, it was observed, in this initial phase, that most patients adhered to the proposed treatment and demonstrated interest in learning and practicing the new concepts. In addition, it was found that the Back School and McKenzie's methods proved to be beneficial strategies in the treatment of patients with chronic non-specific low back pain in short-term for the pain intensity and disability outcomes. However, no differences were observed for trunk flexion ROM for this condition. The study is still in progress. It is expected that patients will remain adherent to the treatments and that the results of the between-group comparisons will be published in a near future.

\section{Acknowledgments : :}

To the Fundação de Amparo a Pesquisa do Estado de São Paulo (FAPESP) for supporting and funding this study.

\section{References $: \because:$.}

1. Airaksinen O, Brox JI, Cedraschi C, Hildebrandt J, Klaber-Moffett J, Kovacs F, et al. Chapter 4. European guidelines for the management of chronic nonspecific low back pain. Eur Spine J. 2006;15 Suppl 2:S192-300

2. van Tulder M. Chapter 1. European guidelines for the management of chronic nonspecific low back pain. Eur Spine J. 2006;15 Suppl 2:134-35

3. Waddell G. The back pain revolution. $2^{\mathrm{a}}$ ed: Edinburgh: Churchill Livingstone; 2004.

4. Walker BF. The prevalence of low back pain: a systematic review of the literature from 1966 to 1998. J Spinal Disord. 2000;13(3):205-17.

5. Costa Lda C, Maher CG, McAuley JH, Hancock MJ, Herbert RD, Refshauge KM, et al. Prognosis for patients with chronic low back pain: inception cohort study. BMJ. 2009;339:b3829.

6. van Middelkoop M, Rubinstein SM, Verhagen AP, Ostelo RW, Koes BW, van Tulder MW. Exercise therapy for chronic nonspecific low-back pain. Best Pract Res Clin Rheumatol. 2010;24(2): 193-204.

7. Costa LO, Maher CG, Latimer J, Hodges PW, Herbert RD, Refshauge KM, et al. Motor control exercise for chronic low back pain: a randomized placebo-controlled trial. Phys Ther. 2009;89(12):1275-86

8. Clare HA, Adams R, Maher CG. A systematic review of efficacy of McKenzie therapy for spinal pain. Aust J Physiother. 2004;50(4):209-16.

9. Engers A, Jellema P, Wensing M, van der Windt DAWM, Grol R, van Tulder MW. Educación del paciente individual para el dolor lumbar. La Biblioteca Cochrane Plus. 2008.

10. Heymans MW, van Tulder MW, Esmail R, Bombardier C, Koes BW. Back schools for acute and subacute non-specific low-back pain. Cochrane Database of Systematic Rev 2004

11. Garcia AN, Gondo FLB, Costa RA, Cyrillo F, Silva TM, Costa LCM, et al. Effectiveness of the Back School and McKenzie techniques in patients with chronic non-specific low back pain: a protocol of a randomised controlled trial. BMC Musculoskeletal Disorders. 2011;12:179

12. Costa LO, Maher CG, Latimer J, Ferreira PH, Ferreira ML, Pozzi GC, et al. Clinimetric testing of three self-report outcome measures for low back pain patients in Brazil: which one is the best? Spine (Phila Pa 1976). 2008;33(22):2459-63.

13. Nusbaum L, Natour J, Ferraz MB, Goldenberg J. Translation, adaptation and validation of the Roland-Morris questionnaire - Brazil Roland-Morris. Braz J Med Biol Res. 2001;34(2):203-10.

14. Costa LOP, Maher CG, Latimer J, Ferreira PH, Pozzi GC, Ribeiro RN. Psychometric characteristics of the Brazilian-Portuguese versions of the Functional Rating Index and the Roland Morris Disability Questionnaire. Spine. 2007;32(17):1902-7.

15. Medicine ACOS. ACSM's Guidelines for exercise testing and prescription. $5^{\mathrm{a}}$ ed. Philadelphia: Lea \& Febiger; 1995

16. Instituto MacKenzie do Brasil. Centro de estudos pós-graduação em diagnóstico e terapia mecânica Manual parte A coluna lombar. Belo Horizonte; 2010

17. Achour Júnior A. Manual de Instruções - Fleximeter - avaliando a flexibilidade. Instituto Code de Pesquisas. Rio de Janeiro: Editora Midiograf; 1997.

18. Lankhorst GJ, Van de Stadt RJ, Vogelaar TW, Van der Korst JK, Prevo AJ. The effect of the Swedish Back School in chronic idiopathic low back pain. A prospective controlled study. Scand J Rehabil Med. 1983;15(3):141-5.

19. McKenzie RA, May S. The lumbar spine: mechanical diagnosis and therapy. $1^{\text {st }}$ ed. Waikanae: New Zealand: Spinal Publications; 2003.

20. May S, Donelson R. Evidence-informed management of chronic low back pain with the McKenzie method. Spine J. 2008;8(1):134-41.

21. Machado LA, de Souza MS, Ferreira PH, Ferreira ML. The McKenzie method for low back pain: a systematic review of the literature with a meta-analysis approach. Spine (Phila Pa 1976). 2006;31(9):E254-62.

22. Skikic EM, Suad T. The effects of McKenzie exercises for patients with low back pain, our experience. Bosn J Basic Med Sci. 2003;3(4):70-5.

23. Andrade SC, Araújo AG, Vilar MJ. [Back school for patients with non-specific chronic lowback pain: benefits from the association of an exercise program with patient's education]. Acta Reumatol Port. 2008;33(4):443-50.

24. Toscano JJO, Egypto EP. A influência do sedentarismo na prevalência de lombalgia. Rev Bras Med Esporte. 2001;7(4):132-7.

25. Chung TM. Escola de coluna: experiência do Hospital das Clínicas da Universidade de São Paulo. Acta Fisiátr. 1996;3(2):13-7.

26. Kisner C, Colby LA. Exercícios terapêuticos fundamentos e técnicas. $5^{a}$ ed. São Paulo: Manole; 2005.

27. Silva ACLG, Mannrich G. Pilates na reabilitação: uma revisão sistemática. Fisioter Mov. 2009;22(3):449-55. 
Appendix 1. Summarised description of the treatment programs

\begin{tabular}{|c|c|c|}
\hline & McKenzie Method ${ }^{16,19}$ & Back School Method ${ }^{18,23,25}$ \\
\hline 1st week & $\begin{array}{l}\text {-Presentation of the proposed methods, history, and general } \\
\text { information about the course; } \\
\text {-Completion of the exercises after initial evaluation results and } \\
\text { indication of preference: flexion, extension, or lateral displace- } \\
\text { ment of the back; } \\
\text {-Educational component: basic information about the lower back } \\
\text { and its structure; mechanical pain; how and why to do exercises; } \\
\text { and types of responses that can occur in response to the exercise; } \\
\text {-Guidance on completing the exercises at home. }\end{array}$ & $\begin{array}{l}\text {-Presentation of the proposed methods, history, and general infor- } \\
\text { mation about the course; } \\
\text {-Anatomy and biomechanical notions of the back; } \\
\text {-Epidemiology; } \\
\text {-Muscle function and its influence on the back; } \\
\text {-Physiopathology of the principal disorders that negatively affect } \\
\text { the back; } \\
\text {-Principal treatment modalities. }\end{array}$ \\
\hline 2nd week & $\begin{array}{l}\text {-Continuation of the exercises defined after the } 1 \text { st session and } \\
\text { progression towards other positions in line with the responses of } \\
\text { the patient. } \\
\text {-Educational component: basic information about the most com- } \\
\text { mon causes of low back pain, emphasising posture when seated } \\
\text { for a prolonged time; practice on finding the correct seated posi- } \\
\text { tion and maintenance of back lordosis in this position. } \\
\text {-Guidance on continuing exercises at home. }\end{array}$ & $\begin{array}{l}\text {-Variation of the mechanical force in diverse movements of the } \\
\text { back; } \\
\text {-Relaxation posture; } \\
\text {-Guidance on positions when seated or standing; } \\
\text {-Instruction on breathing exercises, kinaesthetic training, stretching } \\
\text { of the low back, quadriceps, and hamstrings; } \\
\text {-Guidance on completing exercises at home once a day. }\end{array}$ \\
\hline 3rd week & $\begin{array}{l}\text {-Continuation of the exercises defined after the } 1 \text { st session and } \\
\text { progression towards other positions in line with the responses of } \\
\text { the patient. } \\
\text {-Educational component: basic information about the most com- } \\
\text { mon causes of low back pain; emphasising work on curved posi- } \\
\text { tions; standing up; relaxing after vigorous activity; remaining in the } \\
\text { standing position for prolonged periods; lying down; and resting, } \\
\text { coughing, and sneezing. } \\
\text { - Guidance on continuing the exercises at home. }\end{array}$ & $\begin{array}{l}\text {-Observation of the exercises completed at home; } \\
\text {-Instruction on exercises for abdominal muscular strength; } \\
\text {-Practical application of techniques for articular protection; } \\
\text { - Guidance on how to perform the exercises at home once a day. }\end{array}$ \\
\hline 4th week & $\begin{array}{l}\text {-Continuation of the exercises defined after the } 1 \text { st session and } \\
\text { progression towards other positions in line with the responses of } \\
\text { the patient. } \\
\text {-Educational component: review of the most important points since } \\
\text { the first week. }\end{array}$ & -Practical application of all the exercises and learned techniques. \\
\hline
\end{tabular}


Appendix 2. Description of the exercises

\section{McKenzie Method ${ }^{16,19}$}

Exercise

\begin{tabular}{|c|c|}
\hline Trunk Flexion & $\begin{array}{l}\text { Lying down: dorsal decubitus with knees and hips flexed and feet supported } \\
\text { in the stretch. The patient is instructed to raise the knees towards the chest, } \\
\text { applying extra pressure with the hands towards the knees. } \\
\text { Seated: seated in a chair with the knees and hips at } 90 \text { degrees, the patient } \\
\text { shifts the trunk towards the front, until the head is between the knees and the } \\
\text { hands are as close as possible to the floor. For the most effective effect, the } \\
\text { patient can hold the ankles bringing the trunk even closer to the front. } \\
\text { Standing: with the feet placed shoulder-width apart, the patient places his } \\
\text { hands on the front part of the thighs gliding them as much as possible in the } \\
\text { direction of the floor keeping the knees extended. }\end{array}$ \\
\hline Trunk Extension & $\begin{array}{l}\text { Lying down: patient begins in ventral decubitus with the palms of the hands } \\
\text { facing down below the shoulders. Patient extends the elbow, elevating the up- } \\
\text { per part of the body, while the pelvis and the thighs remain relaxed. } \\
\text { Standing: with the feet placed shoulder-width apart and the hands placed at the } \\
\text { base of the low back with fingers pointed towards the floor, incline the trunk } \\
\text { backwards for as long as possible, keeping the head relaxed. }\end{array}$ \\
\hline Lateral Displacement & $\begin{array}{l}\text { Standing with upper arm support: with the feet placed shoulder-width apart } \\
\text { and the upper arm supine at } 90^{\circ} \text { of elbow flexion in contact with the lateral } \\
\text { trunk toward the shifting side, using the other hand, shift the pelvis to the side } \\
\text { supported by the upper arm. } \\
\text { Standing with wall support: with the feet placed shoulder-width apart, support } \\
\text { one of the upper arms on the wall and use the other hand to shift the pelvis in } \\
\text { the direction of the wall. }\end{array}$ \\
\hline
\end{tabular}

Series

3 sets with 10 repetitions

Could be performed sequentially with a small break between them or divided at distinct times of day in accordance with the responses of the patient.

\section{3 sets with 10 repetitions}

Could be performed sequentially with a small break between them or divided at distinct times of day in accordance with the responses of the patient.

\section{3 sets with 10 repetitions}

Could be performed sequentially with a small break between them or divided at distinct times of day in accordance with the responses of the patient.

\section{Back School Method 26,27}

\begin{tabular}{l}
\hline Exercise \\
\hline Diaphragmatic breathing \\
\hline $\begin{array}{l}\text { Stretching of the erector spinae } \\
\text { muscles }\end{array}$ \\
$\begin{array}{l}\text { Stretching of the musculature posterior } \\
\text { to the lower members }\end{array}$
\end{tabular}

Position

Seated, inhale slowly and deeply through the nose, elevating the abdomen. Breathe air out the through the mouth, raising the navel in the direction of the back.

Dorsal decubitus with flexed knees and supported feet. Bring first one knee and then the other toward the thorax, join the hands across the thighs, and push them in the direction of the thorax.

Dorsal decubitus with one of the legs supported on the mattress and the other flexed approximately $90^{\circ}$ at the hip and knees extended, maintained with help from a bed sheet.

Lying down in lateral decubitus over the member that will be stretched with the

Stretching of the musculature anterior to the hips

Kinaesthetic training

Strengthening of the abdominal musculature hip in a neutral position and knees flexed. Raise the heel of the leg underneath in the direction of the gluteus, keeping the back aligned. Contralateral member in triple flexion of $90^{\circ}$ and the internal side of the knee supported by the mattress. Seated, move the pelvis, making a front and back pelvic inclination at a comfortable range.

a) Dorsal decubitus with two feet supported on the mattress, upon exhaling raise head, shoulders, and thorax, with arms placed at the side of the body, maintaining the alignment of the head with the cervical, transverse muscular contraction of the abdomen, pelvic floor, and paravertebral.

b) Dorsal decubitus with head supported on the mattress, hands at the side of the body. With an extension of the knee of one leg, raise it in the direction of the mattress surface, while the other remains in triple flexion in contact with the trunk. Before the extended leg touches the mattress, alternate the movement bringing it in flexion, while the other is stretched. The leg extension should be performed while exhaling, maintaining transverse muscle contraction of the abdomen, paravertebral, and pelvic floor.

\section{Sets/Duration}

1 set with 10 repetitions

30 seconds

Repeat 10 times

30 seconds

Repeat 10 times

30 seconds

Repeat 10 times

1 set with 10 repetitions

a) 1 set with 10 repetitions

b) 1 set with 10 repetitions for each leg. 